\title{
AS BRETAÑAS NO PARATEXTO DE ÁLVARO CUNQUEIRO*
}

\section{María Xesús Nogueira}

Universidade de Santiago de Compostela

DOI: $10.17075 / g b o c .2020 .010$

* Reprodución do texto lido no Congreso Galicia-Bretaña: un enfoque comparado de dous finisterrae europeos. 

Entre os autores que construíron pontes entre a Bretaña e Galicia, Cunqueiro ocupa, sen dúbida, un lugar de excepción, até o punto de podermos falar dunha verdadeira integración no seu proxecto literario do que chamarei, nun sentido extenso, «materia bretoa». O escritor escolleu ademais un personaxe da tradición artúrica para se incorporar, coa súa primeira novela en galego, á tarefa de restaurar a literatura da posguerra. A publicación de Merlín e familia (1955) supuxo un punto de inflexión no discurso narrativo galego que a crítica cualificou como «literatura da imaxinación», «literatura fantástica», «realismo marabilloso»e, nas lecturas máis hostís, «escapismo». Alén destas etiquetas, Cunqueiro deulle á materia da Bretaña un tratamento innovador ao traer a Galicia a don Merlín e doña Ginebra, nun exercicio de reescritura lúdica e ao tempo subversiva a respecto de modelos anteriores (por exemplo, Cabanillas). Un ano despois da publicación de Merlin e familia, Cunqueiro deu ao prelo As crónicas do sochantre (1956), ambientada na Bretaña do século XVIII.

As dúas primeiras novelas de Álvaro Cunqueiro recrean as dúas Bretañas que conviven na súa narrativa:

a) A literaria e lendaria, coñecida como "materia da Bretaña», reescrita en Merlín e familia e presente tamén en El año del cometa, Os outros feirantes e numerosos artigos de prensa.

b) A imaxinada e literaturizada n'As crónicas do sochantre.

$\mathrm{Na}$ miña achega vou centrarme nun aspecto da obra de Cunqueiro que me parece especialmente relevante en canto obxecto de estudo, como é o paratexto, entendido a partir de Gérard Genette como aqueles elementos que acompañan o texto e que o converten en tal: a capa, o título, os prólogos, as dedicatorias e os índices (peritexto), así como as entrevistas, os artigos etc. (epitexto).

Son varias as razóns que me levaron en diferentes momentos a reparar neste corpus, non demasiado estudado no caso de Cunqueiro:

- A súa extensión: títulos, títulos de partes e capítulos, limiares e epílogos, índices onomásticos...

- A capacidade de transgresión que o autor mostrou neles: títulos extensos e ricos en información (Merlín e familia i outras historias, Si o vello Sinbad volvese ás illas, El año del cometa con la batalla de los cuatro reyes), notas introdutorias e finais por veces duplicadas, índices onomásticos que van moito máis alá da súa función e acaban convertidos en microrrelatos. 
Partindo da convicción de que Cunqueiro extremou a súa capacidade de experimentación e subversión no corpus paratextual, e tamén da centralidade que paradoxalmente lle concedeu na súa obra, levarei a cabo unha análise do tratamento que nel fai da Bretaña como universo de referencia e, sobre todo, de ficción.

\section{OS TÍTULOS}

Os numerosos títulos que identifican a narrativa de Cunqueiro caracterízanse, como xa adiantei, pola súa extensión e complexidade. Alén diso, apréciase neles unha vontade de tematización dos personaxes protagonistas. Tal acontece en $\mathrm{Mer}$ lín e familia e outras historias, no cal tematiza o mago da tradición artúrica e incorpora, mediante a expresión fraseolóxica «e familia», outros personaxes. As crónicas do sochantre, a única das narracións ambientadas na Bretaña, non incorpora, no entanto, ao seu título ningunha referencia toponímica. Estas tampouco están presentes nos rótulos das diferentes seccións que conforman a obra, "A carroza», "As historias», "Os viaxes».

Fóra de Merlín e familia e do relato "Tristán García», d'Os outros feirantes, ningunha obra do mindoniense mostra no seu título referencias á Bretaña. Este elemento identificador non semella para o escritor un lugar acaído para representar ou (hiper)ficcionalizar a realidade bretoa.

\section{OS LIMIARES E OS EPÍLOGOS}

Diferente aproveitamento fai o escritor das notas introdutorias e finais das súas obras. No paratexto que precede a Merlín e familia, a Bretaña lendaria aparece representada polo personaxe de Merlín a través da evocación do seu paxe e narrador da novela, Felipe de Amancia. O espazo de ficción do mago é substituído xa no limiar pola xeografía galega de Miranda. A localización e o punto de vista narrativo mantéñense na nota final, na cal un Felipe de Amancia nostálxico recupera o recordo «da familia que pasou por Mirada en procura da cencia do señor Merlín». 
A autotradución ao castelán amplía a versión orixinal con apéndices entre os que figura a sección «Noticias varias de la vida de don Merlín, mago de Bretaña». Nótese a presenza do topónimo na aposición, que funciona a xeito de título.

A propensión cunqueiriana a estender o paratexto apréciase de novo n'As crónicas do sochantre, que presenta unha duplicación do limiar. O primeiro dos paratextos exerce unha das súas funcións habituais, a indicación do contexto, cunha detallada descrición da Bretaña: «Bretaña é unha terra mui apenedada pola banda do mar, namentras por onde se apega a Francia ábrese en longas chairas, estreitas valiñas e ledos outeiros».

A descrición dunha paisaxe humana na que convive «xente natural de sobremundo" con «doados e mui alertantes pasaxeiros, xentes das soterradas alamedas, difuntos vespertinos, pantasmas, hostes cabaleiras [e] ánimas remitíndose de obrigas» anticipa o fío argumental da obra, a subida do sochantre a unha carroza na que viaxan almas en pena. A voz narrativa da primeira nota introdutoria menciona aínda outro aspecto que está na cerna da obra cunqueiriana, como é o feito de narrar. $\mathrm{O}$ "gusto por contar historias», que o mindoniense ten reiterado en numerosas ocasións, aparece contextualizado na Bretaña e salientado como un dos trazos caracterizadores da súa ancestral idiosincrasia:

Dentro das vilas muradas, nos vellos pazos e castelos ameados, en Rennes ou en Dinan, en Combourg ou en Caradeuc, os sonoros celtas conversan arredor do lume que se alcendeu hai dous mil anos, contando da guerra no mar, das batallas de Hannover, dos pleitos de familia, dos namorados de noutrora.

A segunda das notas limiares d'As crónicas do sochantre está identificada pola letra cursiva e incide de novo na indicación do contexto. Neste caso, o limiar muda o rexistro descritivo polo da crónica para ofrecer datos biográficos do protagonista desde o seu nacemento «o día de san Cosme do mil setecentos e sesenta e dous na vila de Josselin, na doce ribeira do río Oust, en Bretaña de Francia».

A versión castelá d'As crónicas..., elaborada tamén por Cunqueiro, engade un interesante paratexto titulado «Epílogo para bretones». Nel confesa que non viaxara a Bretaña con anterioridade a escribir o libro e identifica as fontes, principalmente literarias, da súa xeografía imaxinada: 
Sepan los bretones que lean este libro que el Autor no ha viajado por su tierra, y todo lo que aquí, en estas Crónicas se cuenta de ella, está tomado de mapas, de libros de viajes, de lecturas de Chateaubriand y Le Goffic, de algunas historias de ciudades y de cartas ejecutorias de las nobles familias, esas cartas encuadernadas en piel de perro, y que vistas de lomo en la Cámara de Rennes, donde dicen que están ordenadas por apellidos mayores y menores, parecerá cada estirpe una jauría de manchados lebreles.

A estas fontes engade no final do paratexto «ocasionales lecturas [...]: Renan, Villiers de l'Isle-Adam, Barbey, etc.». A confesión do escritor opera a xeito de «pararraios» (seguindo a terminoloxía genettiana) ante eventuais críticas á falta de exactitude, ao tempo que reforza a dimensión ficcional.

Por outra banda, no «Epílogo para bretones» Cunqueiro engade unha idea que reiterou en numerosas ocasións: o feito de tomar Galicia, e, en concreto, a paisaxe mindoniense, como modelo para escribir a Bretaña imaxinada:

El campo y las ciudades, los ríos y los vados, los caminos y las ruinas, los he pintado del natural de la tierra mía, Galicia, siendo ambos, el bretón y el galaico, reinos atlánticos, finisterres, parejos en flora y fauna, y provincias vagamente lejanas.

No mencionado epílogo, Cunqueiro engade aínda unha nova fonte ás súas indagacións. Trátase nesta ocasión dunha fonte oral, «Felipe Leven, alias El Francés de Rinlo», un carpinteiro de orixe bretoa que, unha vez lida a novela, corrobora a exactitude entre a Bretaña imaxinada por Cunqueiro e a real: «[M]e dijo que encontraba a su patria en mis relatos tal como él la dejara hace unos cuarenta años».

$\mathrm{O}$ escritor estende neste paratexto a similitude entre Galicia e a Bretaña ao imaxinario e explica que, "[p]ara un gallego, las historias bretonas de fantasmas [...] y héroes [...] tienen el sabor de lo suyo propio». É precisamente esta dimensión ficcional e imaxinativa a que leva a relacionar o escritor a Bretaña imaxinada coa lendaria:

Mirando me quedo en un espejo cómo pasan vientos y nieblas; igual puedo decir: «Ahora pasa, verde y silenciosa, Bretaña de Francia». Por lo fácil que me resulta considerar a Bretaña país de la imaginación y no tierra real, y no es ajeno a ello el que se llamara también Bretaña el país asombroso del rey Artús. 


\section{OS ÍNDICES ONOMÁSTICOS}

Os elementos máis singulares dentro do paratexto cunqueiriano son, sen dúbida, os índices onomásticos, cuxas funcións van máis alá da síntese e a mnemotécnica que lles son propias. Algúns estudosos aludiron á «inestabilidade da diéxese central» que implicaban estas listaxes, ao obrigaren o lector a volver sobre o texto (González Millán), ou á incorporación neles de elementos que forzan a adoptar unha nova perspectiva (Rodríguez Vega). Noutro lugar ocupeime por extenso dos índices cunqueirianos e analicei as funcións que desempeñan dentro do corpus paratextual, tanto as primarias —identificación, cohesión, síntese argumental— como, sobre todo, as secundarias: amplificación do narrado, prolongación na dimensión temporal, función metaliteraria e interpretación.

As dúas novelas de Cunqueiro centradas nas Bretañas incorporan índices onomásticos que presentan algunha diferenza na súa composición. O de Merlín e familia ten un carácter máis heteroxéneo, pois, como acostuma acontecer nos paratextos do autor, ademais de personaxes inclúe animais, seres imaxinarios, lugares e obxectos. O índice identifica os personaxes principais da tradición artúrica reescritos na obra.

MERLÍN. O meu señor amo e mestre, que non digo que na groria esté, porque non teño noticia de que morrese.

GINEBRA, doña. Mi ama, raína que foi de Bretaña. Mui outa, nobre e podeirosa señora.

A voz narrativa do paxe Felipe de Amancia mantense neste índice, que, no caso do protagonista principal, reflicte a distancia temporal á vez que testemuña a atemporalidade do mago. $\mathrm{O}$ índice onomástico incorpora tamén o topónimo Bretaña, na entrada correspondente a dona Ginebra, na cal se fai tamén referencia ao mito do rei Artur:

BRETAÑA. Nación de doña Ginebra, mi ama, que tiña alí un pazo, dúas roseiras e un reiseñor. É un grande reino, deitado de mar a mar, i agora está en partición, que o derradeiro rei, señor Artús, volveuse corvo nunha batalla. 
O paratexto incorpora tamén Avalón e Gaula a propósito de don Amadís e dona Oriana, a pesar de que ningún destes dous personaxes teñen relevancia na diéxese. Nunha multiplicación de niveis ficcionais, dona Oriana aparece mencionada polo feito de ser reproducida a súa imaxe por dona Ginebra nun bordado:

AVALÓN. Illa onde mora don Amadís dende que casou con doña Oriana. É unha das partes máis antigas i esgrevias de Bretaña, i o seu nome quere dicir a misteriosa.

GAULA. Reino e insua no mar aberto, de onde foi a coroa de don Amadís, i agora é parte oculta do partido Imperio de Bretaña.

Un caso semellante é o de don Parsifal, que aparece descrito nos seguintes termos: «PARSIFAL, don. Historia en verso que contaba doña Ginebra, dun cabaleiro de Bretaña que foi en demanda do Graal».

Pola súa banda, o índice onomástico d'As crónicas do sochantre presenta unha singularidade no conxunto de paratextos cunqueiriano ao ter como rótulo «Dramatis personae». En consecuencia, o seu contido está restrinxido aos personaxes e non figura nel a toponimia da Bretaña, que se ve relegada a estes elementos:

a) Ás fórmulas onomásticas, sobre todo a aquelas que imitan o sistema onomástico tradicional nome + lugar de procedencia: o bastardo de Audierne, o mozo do vao do Aulne, o capitán de Combourg, os señores almirantes de Erquy etc.

b) Aos textos das entradas: «un preito en Rennes»; o capitán de Combourg «foi morto por De Crozon o Vesgo no asalto a Château-Josselin»; o sochantre era «racioeiro con menores de Pontivy»; o tío de Mamers o Coxo, «[s]acristán dos franciscos de Quimper» etc.

A incorporación da toponimia artúrica aos índices, xunto coa ausencia de toponimia real no da única obra ambientada en terras bretoas, corrobora a importancia da materia da Bretaña no universo narrativo de Álvaro Cunqueiro. A súa presenza reborda Merlín e familia e esténdese, de xeito esporádico pero significativo, aos paratextos da obra narrativa escrita en castelán: 
ARTURO (EL REY): La flor de las coronas del mundo. Fué rey en Bretaña; dió su nombre a los más alegres veranos. No debe de haber libro en el que por lo menos una vez no se diga su nombre.

(Las mocedades de Ulises)

LANZAROTE DEL LAGO: El signor Capovilla hizo pasar a Fanto, ante la anciana de las joyas en la posada en el camino de Florencia, por un sobrino, y de su mismo nombre, del caballero Lanzarote del Lago.

(Vida y fugas de Fanto Fantini della Gherardesca)

ISOLDA: Es una de esas bellísimas señoras a las que hay que citar, por el dorado cabello, por los ojos azules, porque sonríen y porque lloran, y porque mueren de amor.

(Vida y fugas de Fanto Fantini della Gherardesca)

Arturo e Isolda figuran recollidos nos correspondentes índices en calidade do que noutra ocasión denominei «personaxes nome», que se caracterizan por seren figuras referenciais, pertencentes á literatura universal, e que aparecen simplemente citadas sen teren ningunha relevancia na acción. A Arturo e Isolda habería que situalos, no mapa da ficción cunqueiriana, á beira doutros grandes personaxes como Beatrice, Flamenca e Hamlet, todos eles recollidos igualmente nos índices onomásticos das súas obras.

\section{AS SECCIÓNS FINAIS DE EL AÑO DEL COMETA}

Para finalizar esta análise, cómpre reparar na máis contracanónica e subversiva das reescrituras cunqueirianas da materia da Bretaña, a súa derradeira novela, El año del cometa con la batalla de los cuatro reyes. Aínda que a obra carece de índice onomástico, as lendas artúricas ocupan en certa medida unha marxe, pois aparecen nas dúas seccións finais, máis breves que as que as preceden, e relacionadas coa segunda parte do título, «Los reyes en presencia» e «Audiencia con Julio César. Final».

A singularidade desta reescritura radica na visión degradante dun rei Artur afectado de almorrás e incapacitado, polo tanto, para cabalgar até a batalla se non é medio deitado nunha egua obesa e acompañado dun «oficial de Pomadas» e outro 
«de Clísteres». A representación paródica ten a súa continuidade na imaxe da escaleira que sobe á torre dos Tapices, «donde moraba según los textos la reina Ginebra», con «dos mujeres intentando empalmar por el vientre el cuerpo de cartón de don Galaor» e «[o] tros cuerpos [que] yacían por el suelo, desnudos, mientras de altas perchas colgaban los ricos vestidos». Este rei Artur durmido, co pelo tinguido de verde e chorando porque non ten quen lle bote a pomada das almorrás, resume coas súas propias palabras unha Bretaña de cartón pedra que constitúe unha das imaxes máis elocuentes do carácter contracanónico da reescritura cunqueriana:

— ¡Todo es cartón en Bretaña! ¡Los paladines, los caballos! ¡Hay que figurar que sigue la corte en Camelot! ¿Ves ese bosque? ¡Cartón! Y el cuervo, que es mi contrafigura. Cuando tomo vacaciones, o hago semana inglesa, si viene visita lo presentan como el rey Arturo en la selva de la isla de Avalón.

\section{CONCLUSIÓNS}

As marxes do texto cunqueiriano amplifican, subliñan e prolongan, como tentei demostrar, elementos da narración. O extenso paratexto que o escritor incorporou ás súas obras é, polo tanto, un valioso material para a análise da presenza da Bretaña na súa narrativa. Do estudo dos títulos, notas limiares e finais, así como dos índices onomásticos, é posible extraer as seguintes conclusións:

- Importancia da Bretaña como referente e vontade de deixar constancia, a través do sistema onomástico que nomea os personaxes, da súa toponimia.

- Coherencia do universo lendario coñecido como «materia da Bretaña» no conxunto da narrativa do escritor, máis alá de Merlín e familia: Merlín, Ginebra, Amadís, Oriana, Parsifal, Isolda, Lanzarote e Artur.

- Coherencia que contrasta coas estratexias de descontextualización e integración en novas coordenadas espazo-temporais das que é obxecto esta materia.

As Bretañas lendaria e imaxinada ocupan un importante lugar no paratexto e no conxunto da obra dun autor que, como consecuencia de ler libros de cabalarías, quixo facer «unha especie de remitificación, que poderiamos decir galega», e que, cando «tiña que contar un val [...][,] botou man do val que tiña preto, o do Masma». 